\title{
The role and effects of the third body in the wheel-rail interaction
}

\author{
Y. BERTHIER ${ }^{1}$, S. DESCARTES ${ }^{1}$, M. BUSQUET ${ }^{1}$, E. NICCOLINI ${ }^{2}$, C. DESRAYAUD ${ }^{3}$, L. BAILLET ${ }^{1}$ \\ and M. C. BAIETTO-DUBOURG ${ }^{1}$ \\ ${ }^{1}$ Laboratoire de Mécanique des Contacts et des Solides (LaMCoS), LIMR 5514 INSA de Lyon, Bt fean d'Alembert, 20av. Albert Einstein, 69621 \\ Villeurbanne cedex, France, ${ }^{2}$ RATP, Laboratoire Essais Mesures, 1 bis rue des sablons, 94470 Boissy-Saint-Léger, France, ${ }^{3}$ Ecole des Mines de Saint \\ Etienne, Centre SMS, Laboratoire Plasticité, Endommagement, Corrosion Materiaux-LIMR 5146, 158 Cours Fauriel, 42023 Saint Etienne cedex 2, \\ France
}

\begin{abstract}
A B STRACT This paper focuses on the presence of the third body, a solid interfacial layer in the wheelrail contact. This third bodyis studied from different viewpoints: its presence including composition, thickness and morphology; and its role with respect to its load-carrying capacity, shearing behaviour, transfer of material and finally global friction coefficient. The general approach is phenomenological and is carried out as closelyas possible of the real tribological behaviour of this contact. This paper presents a synthesis of different studies coming from: analysis of specimens taken out periodically from rails and wheels in service, and thus under real contact conditions; and test laboratories, allowing us to impose rolling-sliding conditions with veryhigh precision. From all these studies and results, a better understanding of the role of the third bodyand its influence on friction, adhesion and damage mechanisms (wear, pits, cracks ...) is reached and this is the first step for including its effect in numerical models.
\end{abstract}

Keywords adhesion; friction; interfacial layer; modelling; third body; wear; wheel-rail contact.

\section{INTRODUCTION}

Although trains have been running for more than a century, the tribological phenomena activated in the wheelrail contact are still not completely understood and based mainly on assumptions rather than on rational analysis. The lack in the knowledge of the local contact conditions and their evolution with time makes it difficult to reach a complete understanding and then predict accurately the initiation of headchecking, squats, roaring rail, etc.; although their various consequences have been clearly identified and described. ${ }^{1}$ This situation stems from the difficulty of instrumenting a wheel-rail contact in situ, and both industrial companies and scientists have had to cope as well as they can. Face to this statement the alternative adopted by wheel and bogie manufacturers, as well as rail manufacturers and networks, is to prevent from a catastrophic growth of cracking. Therefore wheel- and rail-reprofiling (grinding) methods have been successfully developed to eliminate surface defects.

Correspondence: Y. Berthier. E-mail: lamcos@insa-lyon.fr
So far, this problem has been addressed independently by many disciplines at different scales, such as

- railway dynamics (global scale),

- contact mechanics (local scale),

- materials, damage (local scale).

Initially, stability studies on vehicles have required boundary conditions to integrate the wheel-rail contact in their modelling. ${ }^{2-4}$ This boundary condition was one single friction value measured from laboratory adhesion tests at starting and stopping. . $^{5,6}$

It did not take long for contact mechanics to become interested in the wheel-rail contact as it provided a model problem: the contact of an unstiffened cylinder and a plane. By taking into account the deformations of the wheel and rail, the reasonable idea of the existence of sticking and sliding zones in the contact plane ${ }^{7}$ was proposed.

This idea, validated experimentally with contacts between polymers/transparent materials, ${ }^{8,9}$ has become a parameter of the wheel-rail contact. On this basis, calculations of stresses and wheel-rail faults became possible both analytically ${ }^{10}$ and numerically. ${ }^{11,12}$ Sticking and 
sliding zones provide two adjusting parameters, which is better than a single friction value. These two friction values were used as the boundary conditions of wheel and rail volume problems.

Progressively, (1) with the improved resolution of models and their solutions and (2) the improved resistance of the materials composing wheels and rails, the limit condition of friction has become a problem in itself. ${ }^{13,14}$ It is now felt necessary to control friction as well as the local phenomena involved in this multi-dimensional problem. This multi-dimensional aspect has led to confusion, because the values of local forces required for contact mechanics result from calculations of railway dynamics based on a global wheel-rail friction parameter, rather than on local friction parameters, such as the sticking and sliding of contact mechanics.

The solution to these problems of scale is now underway. As for contact mechanics, it was possible at a very early stage ${ }^{15}$ to calculate the stresses that have to be compared to the values permitted by the materials. Logically, these admissible values have been sought by carrying out fatigue tests. Thus, criteria have been defined to adapt as much as possible the specific characteristics of 'bulk' fatigue tests under the predominantly 'surface' contact fatigue conditions of wheel-rail contacts. Different criteria and approaches have been formulated, some of them seeing the contact taking place from the surface into the volume, whereas others see the contact taking place more from the volume towards the surface. ${ }^{15-18}$ Each discipline uses its own scientific culture to converge towards a given reality of the wheel-rail contact. This diversity and the absence of in situ onsite measurements has left the field wide open for using adjusting parameters to predict with more or less satisfaction the damage observed on wheels and rails. With the development of numerical ${ }^{19}$ and experimental $^{13}$ techniques it became clear that it was necessary:

- to take into account for not only the surfaces of wheels/rails but also the interface between them, ${ }^{20-22}$ as had been done already for other tribological applications; ${ }^{23,24}$

- that the fatigue tests and damage criteria that always conformed to the nature of the materials, had to brought closer to the actual stress conditions affecting the skin of the wheels and rails.

This paper deals with three main points:

1 In the first part, the presence of this interface or third body is highlighted. ${ }^{25}$

2 In the second part, the role of the third body on the wheelrail contact function is presented. It is shown how the third body flows and accommodates partly the velocity gradients in this contact. The influence of the third body on friction is then presented.
3 Finally, in the third part, the consequences of the presence and action of the third body are discussed in terms of:

(i) the adhesion between the wheel and the rail under starting conditions,

(ii) the wheel-rail contact modelling. The improvements that such an approach could bring to wheel-rail contact modelling is discussed here.

The purpose of this paper is to remain general. Thus the authors have selected experimental results and observations that have contributed to improve the understanding of the wheel-rail contact reality. As a consequence, only a few illustrative data (given contact conditions, types of train, focus on the wheel or the rail, etc.) are presented when necessary for better understanding.

\section{PRESENCE AND ROLE OF THIRD BODY LAYER}

\section{Third body layer}

Artificial and natural third bodies Since the concept of a third body was introduced in tribology, ${ }^{25}$ it has been used in wheel-rail studies in order to generalize the analyses and effects of contaminants: (1) 'climatic' contaminants such as dead leaves, frost, water, (2) 'operational' contaminants such as ballast stones, sand from sand boxes, lubricating oil from the active surface of the rails and (3) products transported (cereals, miscellaneous pollutants, etc.). 5,6

Despite this, these studies took longer to become aware of and admit the presence of an interface composed of particles stemming from the wheels and rails formed during rolling. This interface is composed of a 'natural' third body, whereas the contaminants build up an artificial third body.

The reason for such recent awareness is due to the fact that the thickness of the natural third body is of the same order of the edge effects produced when polishing metallographic sections. The coating of these sections often requires cleaning of the surfaces and thus the partial elimination of the natural third body, whose remains are often confused with white phases.

\section{Condition and techniques to bighlight the natural third body}

Tribological studies conducted on 900A steel rail samples taken from a mixed SNCF and SNCB network (French and Belgium network: passenger and freight), ${ }^{20,26}$ as well as wheels of NF F 01-115 steel from an Alstom 'type BB36000' locomotive, ${ }^{27}$ have pointed out the existence of a third body. The results presented here have been confirmed by other studies, ${ }^{28}$ and under lower loading conditions: metro and tramway, thus ensuring representiveness. Emphasis is placed on the general characteristics of the third body by relying on a selection of representative images chosen for their pedagogical characteristics. 
However, things are more complicated in reality. The selection results from different analysis techniques:

- observations by optical microscopy and scanning electronic microscopy (SEM) and X-ray energy dispersive analysis (EDX),

- metallographic cross-sections of rails and wheels and

- tribological expertise dealing with the surface of rail sections taken after the passage of an increasing number of trains, via polymer replicas made before and after the passage of wheels.

\section{Existence and characteristics of the third body}

Figure 1 is a perspective view of a metallographic crosssection of the rail running surface. It reveals a third body layer with a thickness of $15 \mu \mathrm{m}$. This layer could be interpreted as being a tongue still atomically linked to the first body (and thus different from a crack). The origin and characteristics of this layer are discussed from the analysis of both a rail and wheel cross-sections, and a rail running surface.

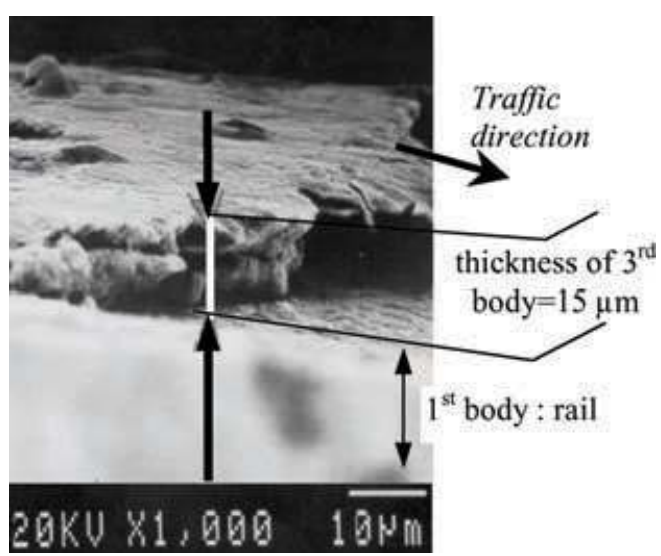

Fig. 1 Perspective view of a metallographic cross-section of the rail running surface.

Fig. 2 Cross-section view of the rail: (a) SEM image and (b) map of (a).
From the EDX analysis (Fig. 2) the concentration of the constitutive components of this layer is different from those of the two first bodies. Furthermore the distribution of iron and oxygen is uniform over a depth equal to that of the layer. Thus this can be interpreted as the result of mixing a volume of material that no longer belongs to the rail (first body).

This last statement is confirmed here by the study of the running surface of a locomotive wheel under starting conditions. $^{27}$ The longitudinal section (in the rolling direction) of an area of the running surface on which only one starting test with sliding had been performed revealed the following layers on the wheel, from the bottom to the top (Fig. 3):

- the bulk with the unchanged metallographic structure of the wheel material (bulk of first body),

- a near-surface layer of about $350 \mu \mathrm{m}$. The grains were reoriented by sliding, according to a well-known fibreing phenomenon, ${ }^{16,29,30}$ as illustrated also in Fig. 18 (the

(d)

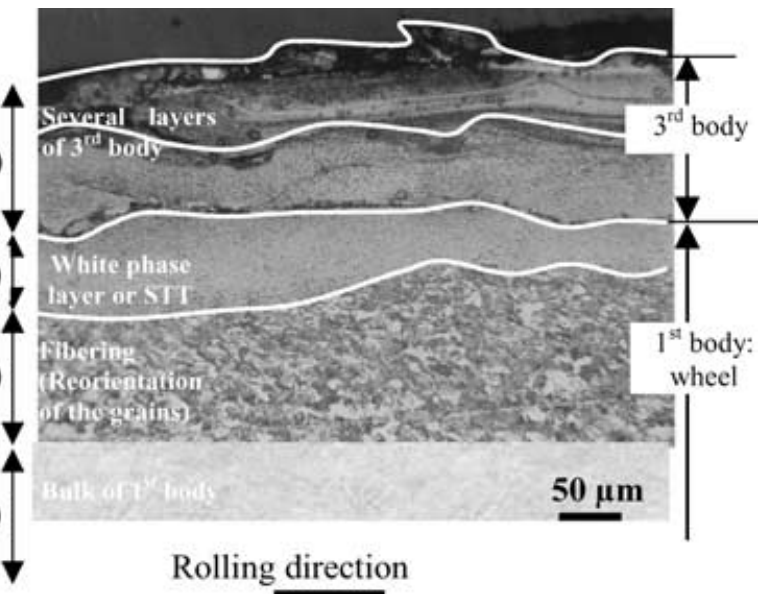

Fig. 3 Cross-section of a wheel with a third body layer.
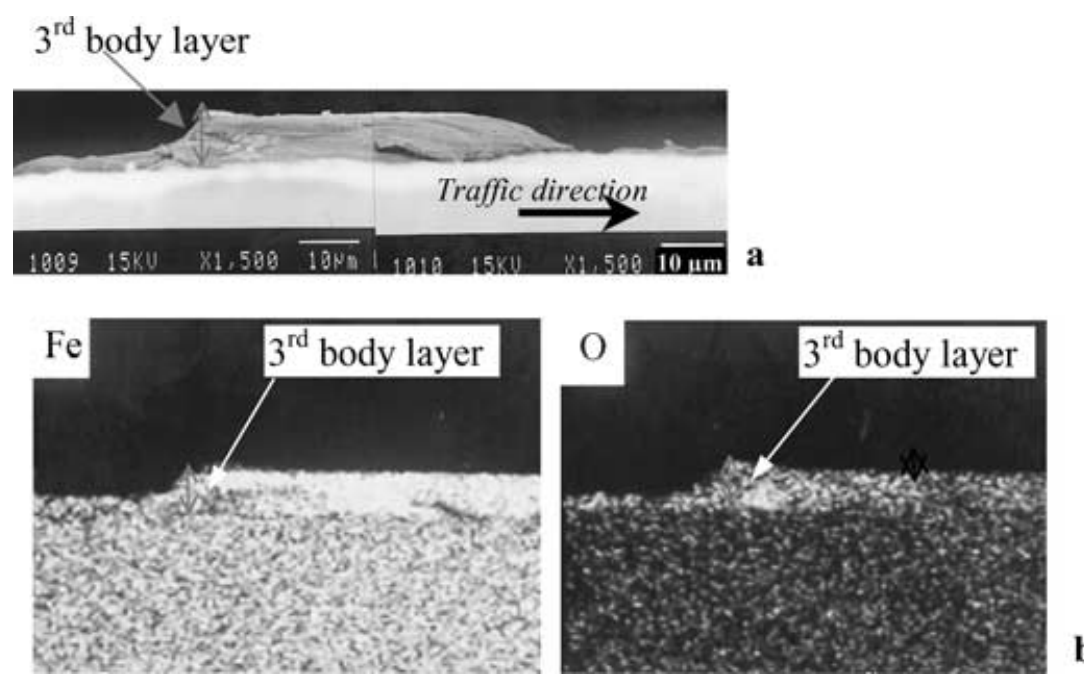
third body has been removed from the specimen in Fig. 18),

- a white phase layer of an average thickness of $50 \mu \mathrm{m}$. More generally, this is a layer of superficial tribological transformation (also called STT) related by epitaxy to the rest of the first body, ${ }^{23,24,31,32}$

- several layers of third body with an overall thickness ranging from 150 to $200 \mu \mathrm{m}$ in this example.

It should be noted that the thickness of the whole third body layer on the wheel is accentuated in this example by the starting condition with strong sliding. Under normal running conditions, except conditions corresponding to start and stop, the thickness of the third body layer is roughly the same for both the wheel and the rail, i.e., one-fifteenth of a micrometer.

These observations show the clear distinction between the white phase layer and the third body layer. These two layers are not atomically linked, i.e. a complete 'interface' between the two layers exists.

Metallographic sections of third body layers on both wheels and rails do not give an image of cohesive layers adhering to first bodies. Indeed, the two layers at the heart of the contact interpenetrate and flow. Thus, depending on the local contact conditions, part of these layers may adhere strongly to one of the first body, while some other part may be ejected from the contact as already filmed. ${ }^{33}$ Consequently, the third body layer present on both wheel and rail is not necessarily continuous and smooth. This is probably why STTs can sometimes be seen directly on the surface of the rail in the form of glitter strips (Fig. 4), and therefore be confused with the third body layer.

As a conclusion, this layer can be formed, deformed, ejected and rebuilt due to the interactions between wheel and rail in the contact. So it is 'strongly modified' and mechanically mixed and the seat of considerable deformation gradients. These capacities lead to a specific behaviour, which dictates the local contact conditions and their evolution with time. This is characteristic of a dynamic behaviour, which will be analysed in the next section. This dynamic behaviour is characterized by what it is called here 'flows of third body'.

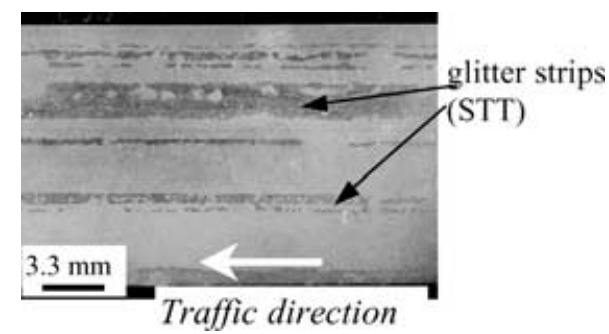

Fig. 4 STT, view of the top of the running surface.

\section{Third body flows}

\section{Techniques to bighlight the third body flows}

To highlight the third body flows, the two following experimental methods have been developed:

1 A technique based on the observation of replica before and after 'contact' to detect the third body flows. Here, a rail running surface is observed before and after the passage of a train.

2 A method using tracers in order to follow the evolution of the third body during traffic. Aluminium powder was placed on the surface of the third body layer of a rail after a record is made by way of a replica in order to trace the progression. The aluminium powder was $99 \%$ pure with AFNOR 'module 21' grain size, and was deposited by gravity.

\section{Contribution of the third body flows to the velocity accommodation}

According to the direction of movement, these flows take place within the contact plane (also called here tangential). Instantaneous contact pressure combined with high shearing gradients imposed to third body may be responsible for this phenomenon. This considerable shearing during the passage of the third body particles in the contact is revealed in Fig. 5. By flowing within the contact the third body particles ejected, or sticking loosely to the wheel or rail after leaving the contact, are stratified.

Furthermore, normal flows perpendicular to the contact plane may sometimes be superimposed. ${ }^{24}$ They are characterized by third body exchanges from wheel to rail and vice versa. But as the wheel and rail constituents are very similar, it is not possible to conclude whether third body particles have been transferred from rail to wheel or vice versa.

But the uniform distribution of oxygen suggests (Fig. 2) that the normal and tangential flows are combined with

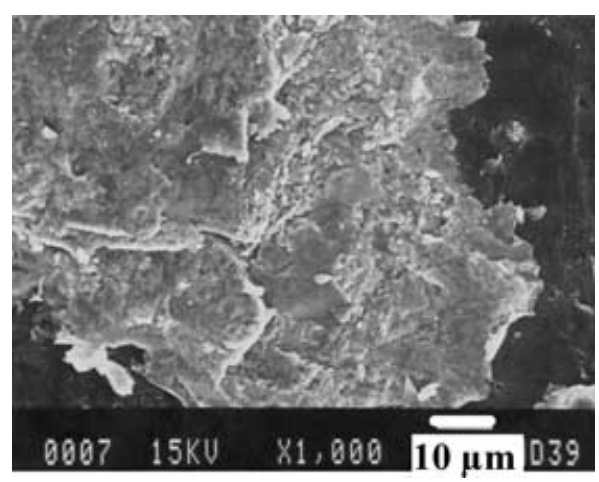

Fig. 5 Strata morphology of the third body (top view) SEM image. 
each other. This gives rise to such a mixed third body layer that it is heterogeneous on the scale of nanoindentation measurements, whose dispersion can reach at maximum $15 \%$ and when measure is possible (problem in case of porosity). ${ }^{27}$ This heterogeneity is expressed by, among other things, porosity. The consequences of the latter will be presented later.

These flows can be visualized by following their fronts. Figure 6 shows the progression, starting from a 'scratch' of the third body, of flows in the region of $100 \mu \mathrm{m}$ obtained after the passage of 20 wheels. Very often, such scratches are interpreted as cracks in the first body, whereas they are only the manifestation of the fronts of third body flows (Fig. 7a). Even when viewing a cross-section, only careful examination distinguishes whether the striation is a crack or the boundary of a flow zone of the third body (Fig. 7b).

These third body flows allow the velocity discontinuities between the wheel and the rail (relative sliding and velocity accommodation). They take place within the sliding and sticking zones described by Kalker's theory. We will see later in this paper the consequences of this on adhesion. This layer can also absorb different contaminants existing on rails, and thus reduce their negative consequences on rail lifetime.

\section{Evolution through time: 'adsorption'}

The aluminium powder was deposited in two heaps with a volume of approximately $50 \mathrm{~mm}^{3}$ spaced $400 \mathrm{~mm}$ from each other according to the direction of the trains. The trains travelled on a straight line without the locomotives exerting any traction force. The powder was not ejected by the displacement of air when the train passed over it, thus it 'passed' through the wheel-rail contact.

After the passage of a train, i.e., 20 wheels, a replica was made at the point where the first heap was placed. After the passage of 16 trains, i.e., 320 wheels, a replica was made at the point where the second heap was placed. SEM observations together with an EDX analysis of the replicas were performed, the latter allowing the determination of the constituents of the third body peeled away from the rail.

After the passage of 20 wheels, the aluminium powder was compacted with little spreading (Figs 8 \& 9).

After the passage of 320 wheels, the powder was spread over the surface of the rail in the rolling direction. The effects of compacting caused by normal force were still visible. As for the effects of tangential force, they were highlighted by spreading powder in the form of small flakes

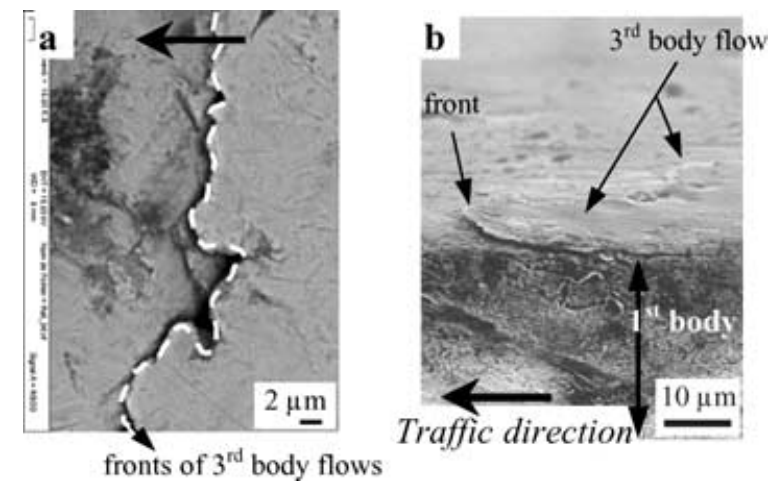

Fig. 7 Third body flows-SEM image: (a) top view and (b) perspective view.

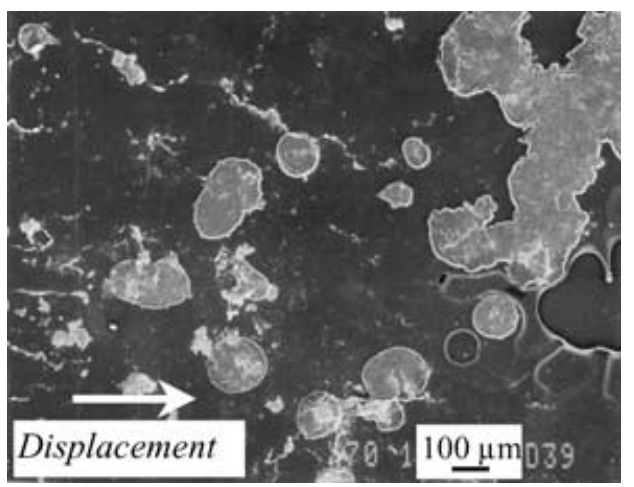

Fig. 8 Aluminium powder after 20 wheels-SEM image. Site of Perrache (Lyon, France).
Fig. 6 Third body flows (top view of the same zone) SEM image: (a) before and (b) after the passage of 20 wheels ( 1 train).
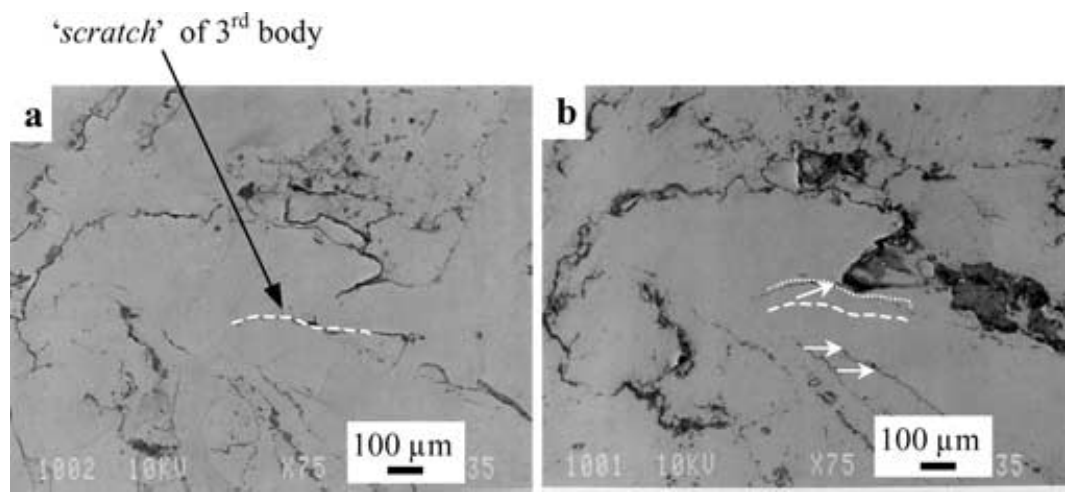


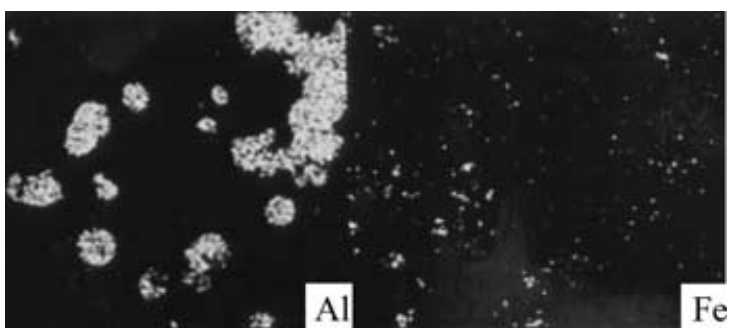

Fig. 9 Aluminium powder after 20 wheels—cartography of Fig. 8.

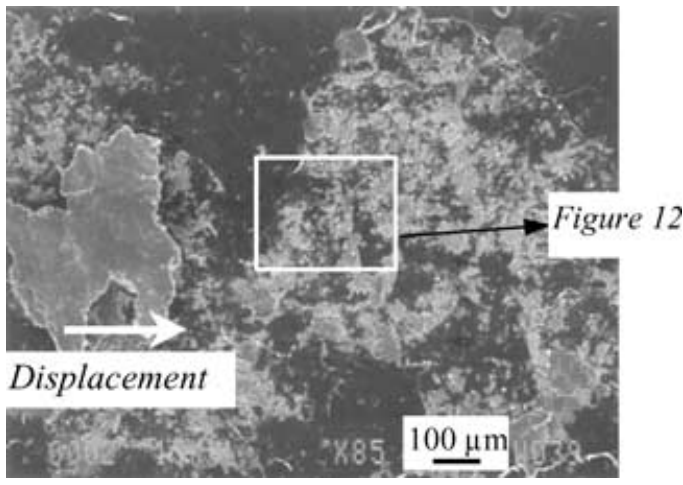

Fig. 10 Aluminium powder after 320 wheels-SEM image. Site of Perrache (Lyon, France).

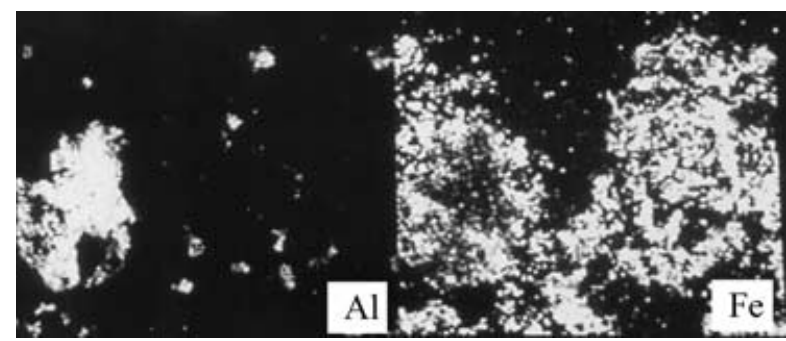

Fig. 11 Aluminium powder after 320 wheels-SEM image at higher magnification than in Fig. 10. Site of Perrache (Lyon, France).

or heterogeneous heaps (Figs $10 \& 12$ ), the heterogeneity being caused by mixing. EDX analysis of the replicas showed that the aluminium powder was deposited 'on' the particles containing iron (Fig. 11). As this analysis was done on a replica that reverses the phenomena, this means that it is the particles containing iron in the contact that 'cover' the aluminium particles all around. Consequently, the aluminium progressively penetrates the natural third body by 'mixing' with it.

This adsorption, or digestion of the artificial third body by the natural third body is confirmed by the EDX analysis of a third body taken from a sample rail. This analysis revealed three main elements: iron, oxygen and silicon, whose distribution was quite uniform as a function of thickness (Fig. 13). The quantity of silicon was also far

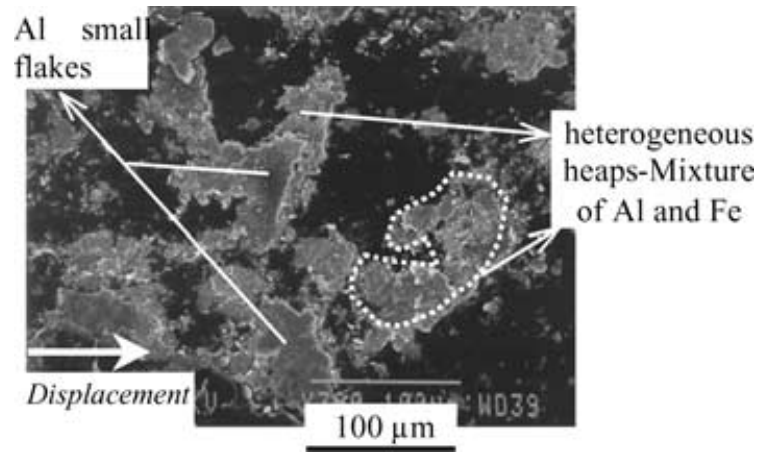

Fig. 12 Aluminium powder after 320 wheels—cartography of Fig. 10.
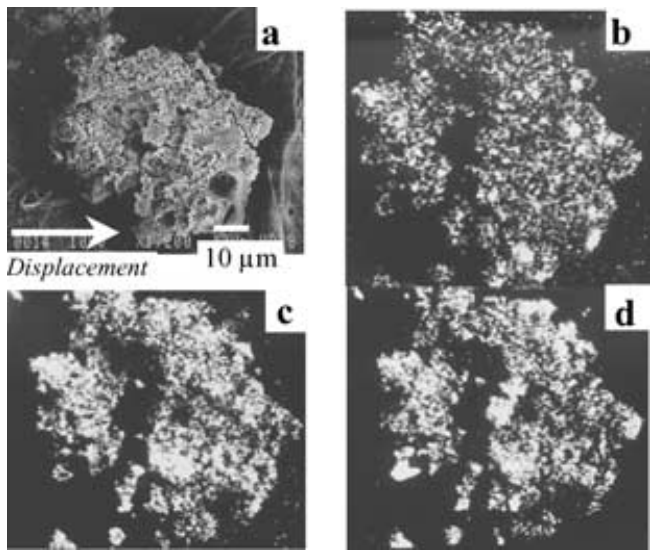

Fig. 13 Third body taken from a sample rail: (a) SEM image, (b) silicon, (c) oxygen and (d) iron. Site of Perrache station (Lyon, France).

higher than the content in silicon of the wheel and rail materials. Consequently, this silicon could come from the sand contained in the sand boxes of the locomotives and pieces of crushed ballast that are progressively digested by the third body layer.

The flows of third body layer on both the wheels and rails accommodate the interfacial sliding, absorb contaminants, respond (react) to normal and tangential stresses, and hence influence local friction. It can be stated that the third body rheology controls wheel-rail contact conditions (see also Refs [21, 34]).

\section{The influence of the third body on friction: validation on a simulator}

This statement may be surprising and due to the onsite measurement difficulties, experiments on a simulator were carried out to test and measure the significant effects of the third body flows on friction. The wide range of real running conditions makes it difficult to have all the corresponding rail samples for examinations. 
Test conditions must fulfil different requirements:

- contact conditions with an emphasis on rolling/sliding ratio,

- friction measurement, for this purpose, a 'roller/plane' contact was carried out.

The main difficulty in carrying out these tests lies in the need to conserve:

- the third body layer present at least on the rails,

- the similarity of conditions regarding the ingestion of contaminants by the roller/rail contact, as the diameter of the roller is less than that of the wheels.

\section{Specimen selection}

The specimen dimensions result from three compromises between:

- The range of the operating conditions of the tribometer: normal load, roller diameter and the sliding parameter.

- The machining of the 'flat' rail specimens from a rail sample taken from a track. This machining had to preserve the third body layer on the test surface (Fig. 14).

- The real geometries of the rails after rolling, which means that the rail specimens are not really flat.

- Sampling the rollers from the material composing the running surface, but without the third body because it was not possible to mount them on a truck to produce the third body layer.

Consequently, even the simulator tests are not fully representative of reality. Therefore, adaptations of test conditions were carried out. This was performed especially by comparing the morphologies of third bodies obtained onsite with those obtained on the simulator. These comparisons are performed by using the third body as a tracer of contact conditions. An atlas of morphologies of third

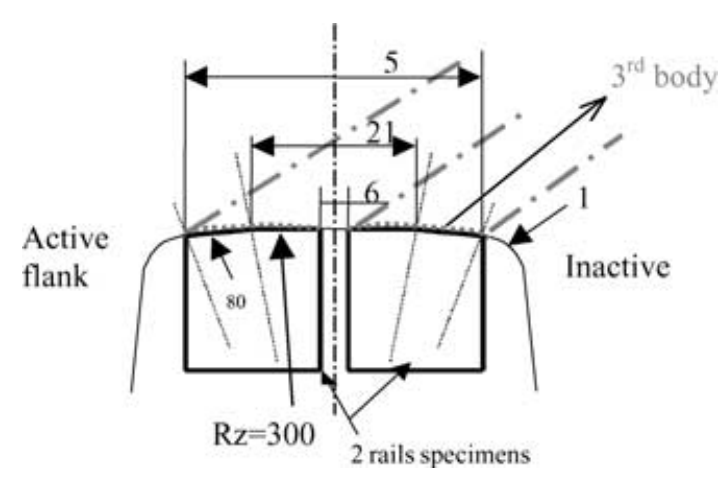

Fig. 14 Specimens extracted from the rail. bodies has been established on the basis of different test conditions imposed by locomotives and wagons. ${ }^{27}$

\section{Test objectives}

One of the objectives was to show that a consequence of mixing of the third body is to make it porous, thus it may play the role of sponge. The role of the third body is presented via the analysis of the friction results obtained during tests with (i) two types of preparation of the natural third body layer, cleaning and stripping, and (ii) the addition of two artificial third bodies, the oil lubricating the active flanks of the rails and the sand used by the locomotives.

1 'Cleaning' was done by wiping cotton soaked in ethyl acetate to eliminate the residue of pollution due handling the specimens and their machining. 'Stripping' was done mechanically by ultrasound and chemically in a trichloroethylene bath, both at a temperature of $50^{\circ} \mathrm{C}$ for $30 \mathrm{~min}$. This stripping eliminates contaminants residues such as lubricant oil on the active flanks of the rails, residues of dead leaves, and sand contained in the surface emerged porosities.

2 Asphaltic oil EP 460 was spread on the third body layer of the rolling-sliding track. The specimen was 'left to dry' for $24 \mathrm{~h}$. The excess oil was removed with a brush before the test. The sand used in the sandboxes of the locomotives was first crushed to obtain a grain size compatible with the diameters of the roller and wheels. What is more, crushing had to be at an acute tangent to obtain a 'powder' whose morphology and adhesion to the third body were similar to those highlighted by the replicas during the tests at the two SNCF sites (French railways). This powder with an average grain size close to $9 \mu \mathrm{m}$ was then distributed over the entire length of the rolling-sliding track, using a pouring apparatus pulled by the simulator.

\section{Tests conditions}

Four series of tests were performed with fixed parameters:

- rail speed: $30 \mathrm{~mm} \mathrm{~s}^{-1}$,

- slip G: 5\%,

- length of the rolling-sliding track: $30 \mathrm{~mm}$

- number of cycles: 130 runs on the rolling-sliding track,

- ambient temperature and atmosphere.

The contact surface on the specimen from the rail was taken from the portion with radius $R_{\mathrm{z}}$ of $300 \mathrm{~mm}$ (Fig. 14). Consequently, and taking into account the previous compromises for working at a Hertz contact pressure of about $1 \mathrm{GPa}$, the roller had a radius of $R_{\mathrm{z}}=40 \mathrm{~mm}$ and a convex with radius $R_{\mathrm{x}}=16 \mathrm{~mm}$ (Fig. 15). The actual value of the contact pressure defined by these radii remains 


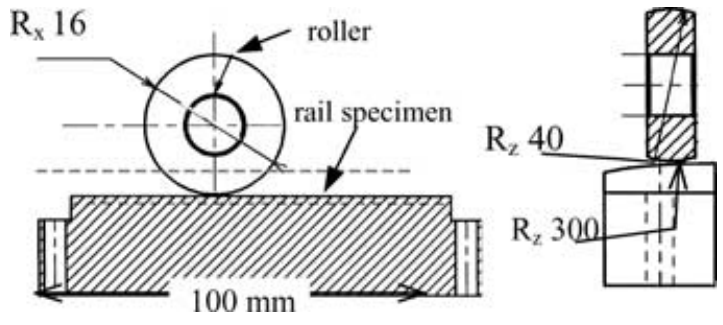

Fig. 15 Roller in contact on a rail specimen.

Table 1 Theoretical conditions of tests

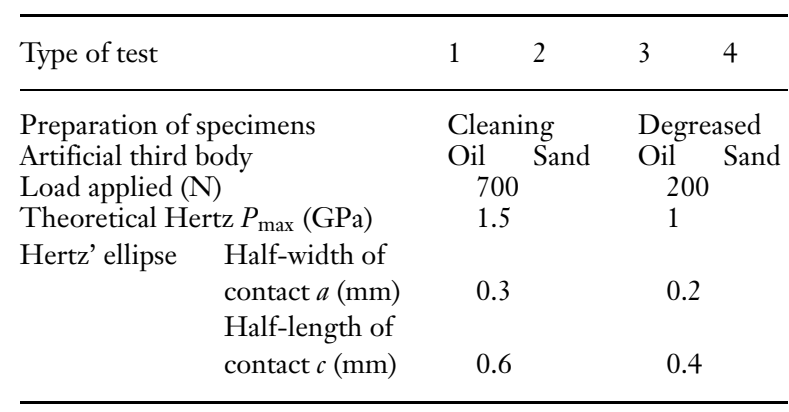

'theoretical' as the real contact conditions on the simulator obviously depend on the real geometry of the surface of the rail specimen and also on the precision of assembling the specimens on the simulator, which in turn depends on the precision of the bearing faces and the setting on the simulator.

The rail specimen with a total length of $100 \mathrm{~mm}$ was fixed on the simulator with an accuracy of $5 \mu \mathrm{m}$ to obtain a contact track whose width over a length of $50 \mathrm{~mm}$ did not vary more than $10 \%$. Lastly, the width of the contact track was adapted by adjusting the normal load, to provide the values of 700 and $200 \mathrm{~N}$ (Table 1). This process seemed to produce local contact conditions that were the closest to those observed onsite.

The train speed was simulated by the linear speed of the rail specimen $\left(V_{1}\right)$. Wheel rotation speed was simulated by the rotation speed of the roller $\left(V_{\mathrm{g}}\right)$. The master-slave control of the simulator permits imposing the sliding, $r$, between the roller and the rail specimen $\left(r=V_{g} / V_{1}\right)$ by taking into account the real radius of the roller when rolling which depends on the relative setting conditions of roller and the rail specimen.

\section{Results and discussion}

After cleaning the specimens, the value of friction coefficient was about 0.07 whether the tests were carried out with one of the artificial third body or not (Fig. 16).

When the specimens were stripped the friction coefficient was 0.4 without the artificial third body. With the

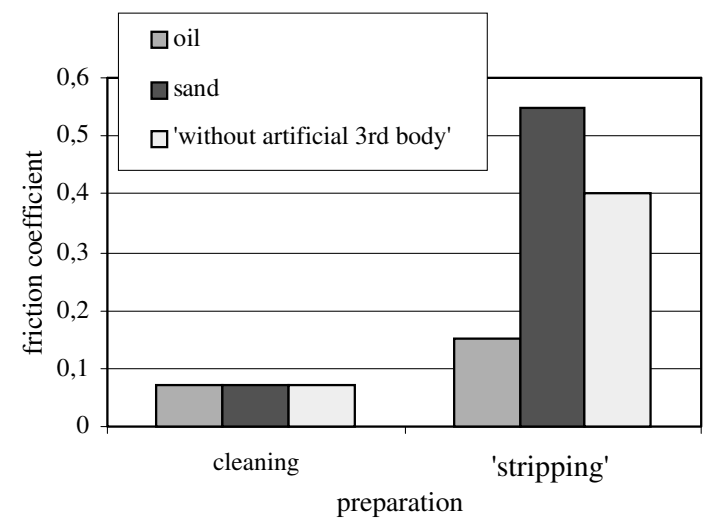

Fig. 16 Effect of third body.

artificial third body it changes to 0.15 with oil and to 0.55 with sand.

When cleaning was performed, the local 'rolling-sliding' conditions caused the porosities of the third body to bleed the residue lubricant from the active flanks of the rails (the lubricant is initially provided at the active side of the rail). This oil-bleeding or migration was formed at the superficial third body layer. This superficial layer, also called 'screens' in Refs [24, 35], is a pollution layer of 20-30 nm and is distinguished here from the third body layer defined in this work $(15 \mu \mathrm{m})$. In the present case, these screens were sufficient to accommodate velocity and whilst not being disturbed by one of the two contaminants brought into contact.

This oil-bleeding was reduced by 'stripping'. With no addition of contaminant, the velocity accommodation occurred in the volume of the third body layer. Lastly, the addition of oil and sand localized velocity accommodation, thereby explaining the trace of the friction behaviour of these two contaminants.

\section{Conclusions on the presence and role of the third body}

Although difficult to highlight, a third body layer of onefifteenth of micrometer thick is present on both the wheel and the rail. In the case of the wheel-rail contact, these two layers joined to become a single layer. Initially composed of particles stemming from wheels and rails, this third body flows into the contact to accommodate the sliding between wheel and rail. These flows can be explained by the instantaneous pressures of the contact and the shearing gradients imposed on the third body.

These flows require that examination of running surfaces of wheels and rails must distinguish contact fatigue cracks from the flow fronts of third body layers.

The exchange third body flows between wheel and rail are capable of progressively absorbing and digesting 
certain solid (sand) and fluid (oil) contaminants. This digestion considerably reduces the risks of cracking caused by indentations made by solid contaminants. ${ }^{36}$ The third body digests a large number of contaminants and has a complex rheology. This is why it can lead to very different friction values ${ }^{33}$ as a function of contact conditions (sliding, pressure, flows, etc.). It also partially controls the rail's lifetime by protecting the two first bodies, while accommodating the velocity discontinuities. At the same time, it also controls the wheel-rail adhesion via its 'degradation and/or reformation' mechanisms.

The study of flow fronts and the local distribution of the third body permits returning to in situ contact conditions. The third body can therefore be used as a tracer of local contact conditions, i.e., a 'three-dimensional sensor', and thus offset the difficulty of instrumenting a contact in situ. The third body is thus a tool to reconstitute service adhesion phenomena. Its presence also questions the real stresses transmitted to the first bodies. Both statements are further developed in the next sections.

\section{CONSEQUENCES OF THE THIRD BODY PRESENCE}

\section{Consequences on adhesion}

To improve safety especially during braking, antiskidding systems are being continuously developed and improved. This is done by the implementation of increasingly sophisticated numerical models based on:

- Kalker's theories (Fig. 17). The evolution of adhesion (adhesion parameter $T / N$ ) as a function of sliding takes place in three parts: (a) a linear part of the pseudosliding phase, (b) a nonlinear part of the pseudosliding phase, (c) the complete sliding phase; and

- more recently on neural networks and fuzzy logic. ${ }^{37}$

This last trend shows that physical phenomena relative to adhesion have never been fully described. In the following example, the third body approach has been successfully applied to correlate physical phenomena, relative to

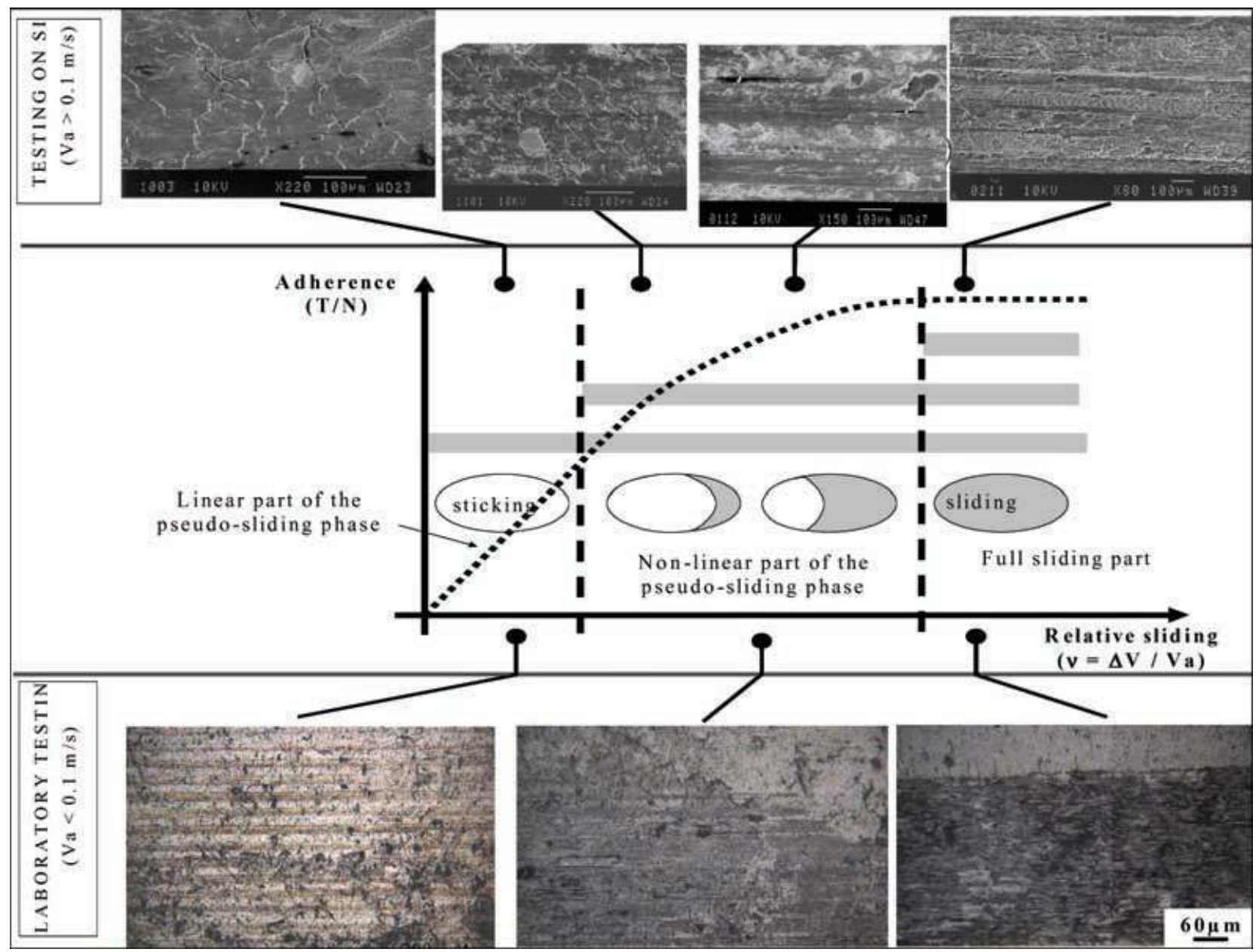

Fig. 17 Evolution of adhesion as a function of sliding for rolling velocities lower than $3 \mathrm{~m} \mathrm{~s}^{-1}$. In parallel, evolution of the third body rheology and flows associated with each adhesion phase $\mathrm{e}^{25,33,46}$ for (1) testing onsite at the top and (2) laboratory testing at the bottom. 
adhesion under starting conditions, to local contact conditions and more global parameters conventionally used for adhesion.

The information contained within the third body can be expressed by its rheological characteristics observed at the skin of the wheel or the rail. ${ }^{27}$ The local evolution of adhesion is dependent on:

- the third body flows (direction, spatial distribution, intensity, nature ... .) as a function of rolling, sliding and environmental conditions;

- the rheology of the different layers observed at the skin of rail and wheel (cross-sections) described in the section 'Existence and Characteristics of the Third Body'.

This volumic description of the rheological characteristics of the third body was analysed (1) during some experiments onsite on a locomotive and (2) during laboratory experiments. These two complementary experimental programmes allowed us mainly to reach these two results:

1 The identification of the role of the third body in the physical mechanisms related to the creation and the evolution of adhesion. At the scale of the contact, the rolling velocity determines the rheological behaviour of the third body, which imposes then the adhesion value when stimulated by the sliding velocity.

2 The use of physical contact conditions, which describe the third body rheological characteristics as a function of the global mechanical, kinematical parameters to replace the empirical contact conditions usually used in numerical models.

Figure 17 presents the summary of these two main results: 'the physical phenomena' related to adhesion are explained and described as a function of sliding for rolling velocities lower than $3 \mathrm{~m} \mathrm{~s}^{-1}$. Each adhesion phase is associated with a third body's morphology. All these results are fully described in Refs [27, 38, 39].

As an example, in case of rolling velocities higher than $0.1 \mathrm{~m} \mathrm{~s}^{-1}$ (onsite), the interpretations are as follows:

1 For sliding within the linear part of the pseudosliding phase, the adhesion coefficient evolution was physically associated with the local flows located at the superficial layer of the third body. This gives rise to a given morphology of third body, as shown in Fig. 17.

2 For sliding within the nonlinear part of the pseudosliding phase, there is an intermediate state where the adhesion coefficient evolution is still partly due to the local flows of the third body. However, a new type of flow was identified: the flows of the particles detached (not elongated) from the rail or the wheel, which can be reintroduced into the contact, also called the recirculation flow.

3 For sliding close to the maximum of adhesion, this recirculation flow becomes predominant and is about to create a wear flow (particles definitively lost for the contact). This recirculation flow (maximal adhesion) is strongly conditioned by the environment, which may or may not degrade the rheological characteristics of the third body (mainly its cohesion) and as a consequence the adhesion level.

In the case of rolling velocities lower than $0.13 \mathrm{~m} \mathrm{~s}^{-1}$ (laboratory tests), in similar conditions as testing onsite (same third body, identical relative sliding, wheel-rail translation movement, i.e., at the scale of the contact area obtained on sites), some new rheological behaviour (when compared to site testing) was identified, explaining the evolution of adhesion for very low sliding velocities. This new rheological behaviour is activated on sites but has not been detected and followed on sites. This completes the adhesion evolution scheme with the activation of some new third body rheological characteristics. This way, all the physical scales are investigated to define the physics of adhesion.

\section{Consequences on damage and on wheel-rail contact modelling}

In this part, our main aim is to integrate more physics into modelling and vice versa to use these models to imagine physics.

Recent modelling work ${ }^{40}$ confirmed the need in some situations to account for the third body in order to get more realistic models. In a comparable way as for third body flows (see the section 'Third Body Flows'), the nearsurface layers $(<300 \mu \mathrm{m})$ of worn rails or worn wheels are often observed to present very large plastic strains mainly in the rolling direction, ${ }^{16,20,27,41,42}$ as shown in a rail longitudinal cross-section in Fig. 18. This 'near-surface' layer refers to the identified layer (b) of the section 'Existence and Characteristics of the Third Body' (fibreing phenomena). In Fig. 18, it is recalled that the third body has been removed. It is now well established that wheel-rail failure is often a result of the accumulation of these plastic strains at the near-surface layers. From this starting point and to investigate this further, elastoplastic finite-element models were developed to simulate the rail mechanical response to the action of a rolling wheel and to correlate with real rail cross-sections. The surface stresses (boundary conditions of the models) were computed using INRETS software, ${ }^{43,44}$ based on Kalker's theories.

Two main discrepancies between computed results and observations are obtained:

1 The computed longitudinal shearing was quite low compared to real distorted near-surface layers; this going in 


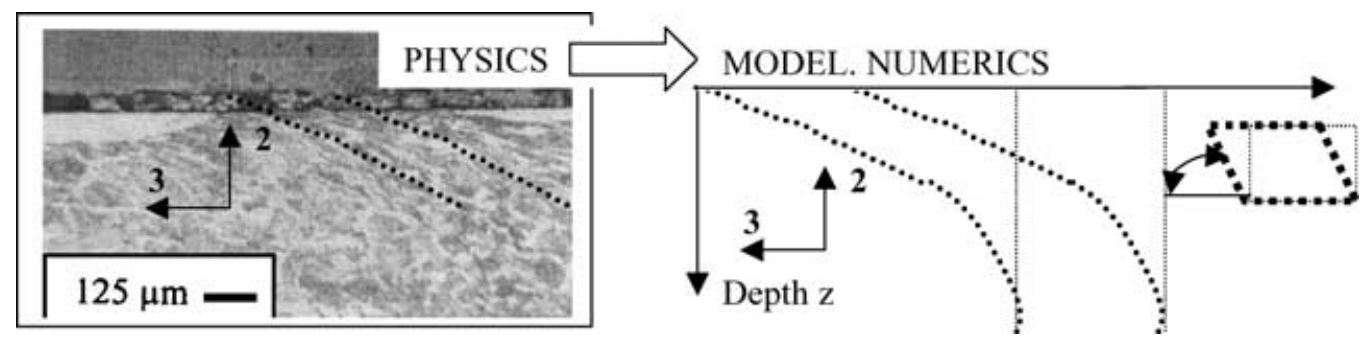

Fig. 18 Correlation between microstructural reorganization of material and plastic strains.

the sense of a kind of fatigue phenomena where material distortion would accumulate.

2 The plastically deformed layer depth predicted by FE models was more important than the one observed on real rail cross-sections $(<300 \mu \mathrm{m})$.

Concerning (1), one of the reasons for the discrepancies is that the skin of the rail is affected and controlled by the hydrostatic pressure, which leads to a different behaviour than expected. ${ }^{45-47}$ The material behaviour in most calculations is taken from data obtained from conventional characterization tests, where high hydrostatic pressure is not taken into account. It becomes now clear that under high hydrostatic pressure the deformability of the material is increased. ${ }^{45,48}$ It is thus not surprising to observe that the near-surface layer of rails accumulates very large plastic strains, without fracture. However, this strain accumulation could be investigated by using cyclic plasticity models, as in Refs [49-51].

Concerning (2) and following experimental evidence set out in this paper, it seems possible that the velocity accommodation between the wheel and the rail takes place at least partly within the third body. Whereas, the resulting loads assessed by train dynamics at the wheel-rail contact are globally reasonable, the location of the frictional energy dissipation is not easy to assess. ${ }^{52}$ If significant frictional energy dissipation takes place within this third body, the boundary conditions at the rail (or wheel) surface, i.e., at the interface between the third body and the rail's nearsurface layers, may be different from the ones predicted by existing theoretical models, ${ }^{11,12}$ which do not account for the solid third body layer as a layer occupying a finite volume. The third body 'tangential effects' could lead to a less severe shearing of the rail's near-surface layers in the case of its adhesion to the rail where it may play the role of a barrier (or coating). Regarding 'normal effects' and in the case of not cohesive solid third body, the load carrying might take place at some islands and this could thus change the scale of the contact. It might decrease the contact area (in the same way as can be observed in the case of rough surfaces) and lead to a less important affected depth within each pass of the wheel. Both effects are quantitatively presented in Fig. 19, where the vari- ations of longitudinal plastic strain (called in this work $\left.\left|\mathrm{SDV}_{7}\right|\right)$ versus the rail depth $z$ are plotted for three traction coefficients (simulation of free traction, accelerating and braking wheel) in a longitudinal rail cross-section. If these computed distortions are compared to a rail nearsurface layer, where the third body still remains (see left part of Fig. 19), one can consider that a part of the frictional energy is dissipated both by shearing of the third body and by plastic distortion in the rail's near-surface layer and that the load-carrying area might be changed.

However, even if further calculations and analysis have to be performed to confirm these points, this questions the relevance of the boundary conditions applied to computational models without considering this point. Future challenges in modelling would be: (1) to understand and predict the material behaviour under high hydrostatic pressure and (2) to go on investigating the interactions between the wheel, the rail and the third body in order to understand the physical local contact conditions and to get more realistic boundary conditions for rail and wheel damage models. A starting point of such an analysis was conducted in the section 'Consequences on Adhesion' under starting conditions. In the same way, recent experimental studies ${ }^{35}$ with solid lubricant have been associated with theoretical studies, such as the development of granular flow models. ${ }^{34}$ These studies constitute significant progress in the understanding of a solid interface and they are a first step in the construction of a rheological model for the solid third body. However, these studies focus on the mechanical and rheological properties of solid layers but they do not integrate yet the deformation of the contacting bodies.

\section{CONCLUSIONS}

The results show the presence of a natural third body ranging in thickness from a few micrometers to several dozen micrometers on the rail and wheel. Initially composed of particles stemming from wheels and rails, it flows into the contact to accommodate the sliding between wheel and rail while absorbing and digesting solid and fluid contaminants.

Whereas the third body appears to make the wheelrail contact analysis more complex, it however strongly 


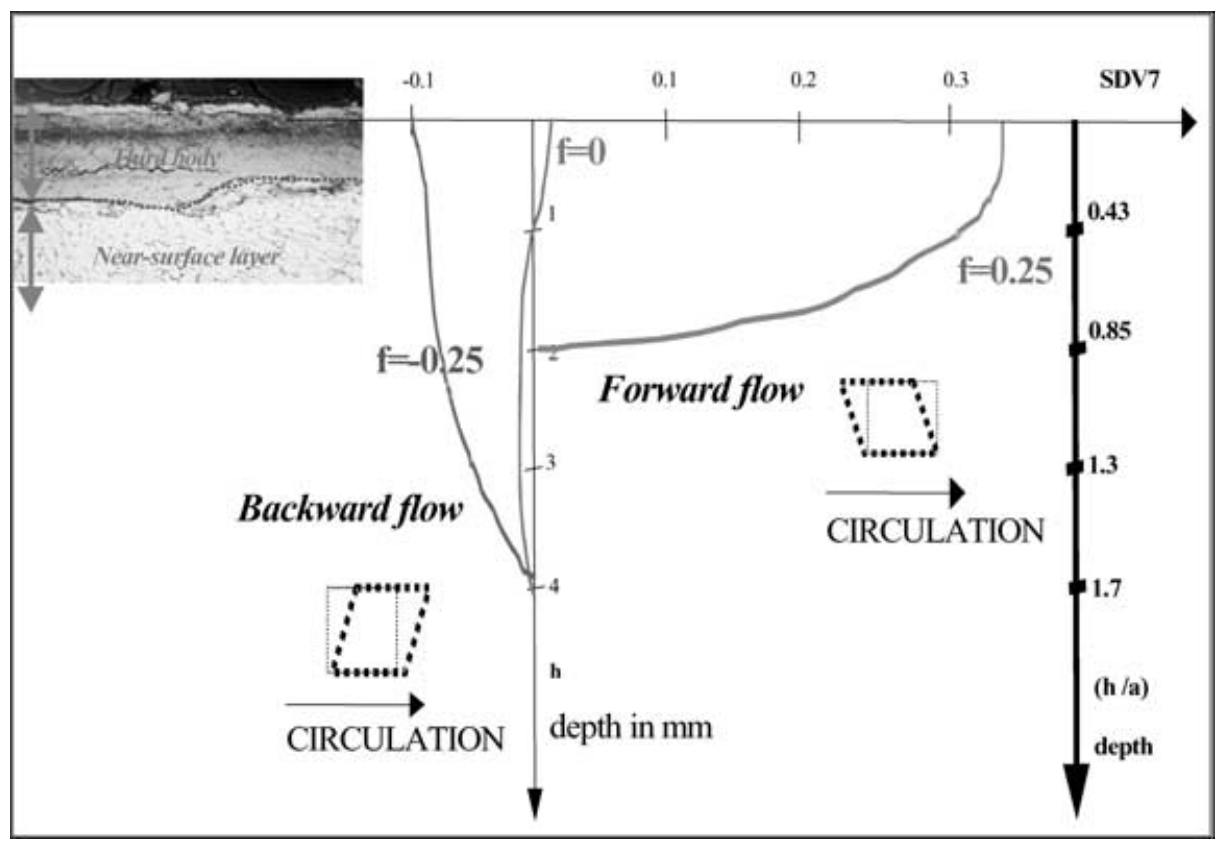

Fig. 19 Potential participation of the third body layer to the transmission of shearing.

contributes to the safety and the reliable functioning of this contact, even though the 'local' behaviour is not fully understood. In other words, without the presence of this third body, the wheel-rail contact would be far less reliable and its life duration considerably shortened. It is clear that existing solid third body models would need further specific research development before being: (1) firstly coupled with wheel or rail damage contact models and (2) finally being integrated to a global 'vehicle/railway' model.

As a consequence, the first step is to establish when this layer should be accounted for and specifically how. For railway dynamics, the third body is indirectly accounted for by a global wheel-rail friction parameter, measured onsite and used as a boundary condition in these models. This parameter may be sufficient regarding the other assumptions made at this macroscopic scale of analysis. However, is this measured friction coefficient the relevant boundary condition even at this macroscopic scale? Friction measurements have always been difficult to interpret and should be used carefully as a 'reasonable' starting point value, but also need to be assessed and adapted in relation with models.

Although the parameter of friction produced by the third body may be sufficient for models of railway dynamics, contact mechanics must progressively take into account the third body in order to improve the precision of calculations of stress gradients and deformations at micrometric scale, because the initiation of degradation probably takes place at a lower scale.
The friction coefficient becomes an excessively reductive concept to represent local phenomena realistically and thus to control them in order to control the adhesion of a wheel, or wear, or to avoid curve derailment. In this last example, it is the lubrication of the active rail flange, which has to be controlled; it is thus more the resulting mixture 'solid third body + fluid third body' that is preponderant. ${ }^{53}$ Only a complete tribological analysis enables one to establish the significant parameters relative to each specific case.

Regarding materials, their contribution as to these two following points has to be evaluated:

$\mathbf{1}$ as contacting bodies (wheel or rail), developing fatigue cracks, STTs ...,

2 as natural third body (particle detachment as described in the section 'Presence and Role of Third Body Layer'). This last point is the least explored way of optimising the tribological qualities of the third bodies.

Thus, a future challenge for materials would be, within the range of loading, to:

1 develop some STTs rather than cracks,

2 develop some STTs, which would lead to a third body with optimal tribological properties.

Regarding contact fatigue, modelling efforts developed during the last five years to better understand and model 
the mechanical local contact conditions, which would lead to the formations of STTs have to go on. It will then be possible to know how to make the models and the material characterization tests evolve. The contribution of the mechanism (vehicle, railways ...) should not be obviously forgotten and integrated in the general approach!

\section{Acknowledgements}

The authors would like to thank Mrs M. Cassard for her expertises, which permitted highlighting the layer of third body, and Mr Godeau and Mr Lafarge for their technical assistance. The authors would also like to thank SNCF (French railways) and Alstom Transport for supplying the sites, pieces of rails and locomotives, financial aid and their permission to allowing the authors to use the information obtained during the tests onsite. The authors wish to acknowledge the INRETS for letting us their software to provide the inputs of the FE models.

\section{REFERENCES}

1 Alias, J. (1987) Le Rail, Eyrolles, Paris, France, p. 677.

2 Grassie, S. L., Gregory, R. W., Harisson, D. and Johnson, K. L. (1982) The dynamic response of railway track to high frequency vertical excitation. 7. Mech. Engng Sci. 24, 77-90.

3 Grassie, S. L., Gregory R. W. and Johnson, K. L. (1982) The dynamic response of railway track to high frequency lateral/longitudinal excitation. 7. Mech. Engng Sci. 24, 91-102.

4 Theiler, A., Knothe, K. and Gueney, S. (2000) Investigation of contact stresses on the wheel-rail system at steady state curving. In: The Dynamics of Vebicles on Roads and on Tracks (Edited by R. Fröhling). Proceedings of the 16th IAVSD Symposium, Pretoria, South Africa, 1999. Vebicle Syst. Dyn. 29(Suppl).

5 Boiteux, M. (1985) Adhérence en freinage et anti-enrayeurs: Synthèse des connaissances actuelles sur l'adhérence, Utrecht, Netherlands, ERRI, Rapport No. B164/RP1, p. 58.

6 Boiteux, M. (1998) Le Problème de l'adhérence en freinage. Revue Générale des Chemins de Fer 452, 28-40.

7 Carter, F. W. (1926) On the action of a locomotive driving wheel. Proc. Royal Society London A 112, 151-157.

8 Barquins, M. (1996) Les forces de Van Der Waals-Les théories de l'adhésion-application au collage. Colloque Metasport "Collage, tissus biologiques et biomatériaux-perspectives en chirurgie orthopédique et orthodontie", Paris, France, pp. 12-22, 1996.

9 Maugis, D. (1997) Adhérence des solides, aspects mécaniques, Revue Métallurgique Cab Inf Tech, 655-690.

10 Johnson, K. L. (1958) The effect of a tangential contact force upon the rolling motionof an elastic sphere upon a plane. $\mathcal{F}$. Appl. Mech. 15, 339-346.

11 Kalker, J. J. (1979) Survey of wheel-rail rolling contact theory. Vebicle Syst. Dyn. 5, 317-358.

12 Kalker, J. J. (1990) Three-dimensional elastic bodies in rolling contact. In: Solid Mechanics and its Application, Vol. 2. Kluwer Academic Publishers, Dordrecht, p. 314.

13 Clayton, P. (1996) Tribological aspects of wheel-rail contact: A review of recent experimental research. Wear 191, 170-183.
14 Harrison, H., McCanney, T. and Cotter, J. (2002) Recent developments in coefficient of friction measurements at the rail/wheel interface. Wear 253, 114-123.

15 Dang Van, K. and Maitournam, M. H. (2000) On a new methodology for quantitative modeling of fretting fatigue. In: Fretting Fatigue: Current Technology and Practices, ASTM STP 1367, pp. 538-552.

16 Bertrand, J. P., Galtier, A., Guelton, N., et al. (1997) Phase blanche dans les rails: Caractères métallurgiques et approche mécanique sur les conditions de formation, IRSID, Note No. MPM 97N 1126, Mézières, France, p. 38.

17 Dubourg, M. C. and Kalker, J. J. (1993) Cracks behaviour under rolling contact fatigue. FRA-ERRI International Conference in Rail Quality and Maintenance for Modern Railway Operation, Delft, NL, 24-26 juin 1992. Kluwer Academic Publishers, pp. 373-384.

18 Dubourg, M. C. and Lamacq, V. (2000) Stage II crack propagation direction determination under fretting fatigue loading. A new approach in accordance with experimental observations. In: Fretting Fatigue: Current Technology and Practices (Edited by D. Hoeppner, V. Chandrasekaran \& C. B. Elliott). ASTM 1367, pp. 436-450.

19 Baillet, L. and Sassi, T. (2002) Méthode d'éléments finis avec hydridisation frontière pour les problèmes de contact avec frottement. C.R. Acad. Sci. Paris, Ser. I 334, 917-922.

20 Cassard, M. and Berthier, Y. (1996) Analyse tribologique de la surface de roulement des rails de la zone d'essai d'Epernay. Report LMC/SNCF, 6, GT Fatigue de Contact, p. 52.

21 Hou, K., Kalousek, J. and Magel, E. (1997) Rheological model of solid layer in rolling contact. Wear 211, 134-140.

22 Ghonem, H., Kalousek, J., Stone, D. H. and Dibble, D. W. (1982) Observations of rail wear on heavy haul railway lines. Contact Mechanics and Wear of Rail/Wheel Systems. University of Waterloo Press, pp. 249-269.

23 Descartes, S. and Berthier, Y. (2002) Rheology and flows of third body: background and application to an $\mathrm{MoS}_{1.6}$ coating. Wear 252, 546-556.

24 Berthier, Y. (2001) Background on friction and wear. In: Lemaître Handbook of Materials Behavior Models. Academic Press, pp. 676-699.

25 Godet, M. (1984) The 3rd body approach: a mechanical view of wear. Wear 100, 437-452.

26 Descartes, S., Desrayaud, C., Niccolini, E. and Berthier, Y. (2003) The presence and the role of the 3rd body in a wheel-rail contact. In: Proceedings CM2003, 6th International Conference on Contact Mechanics and Wear of Rail/Wheel Systems, Gothenburg, Sweden, pp. 333-342.

27 Niccolini, E. (2000) PhD Thesis 'Adhérence roue-rail en traction réalité tribologique en condition de démarrage', INSA de Lyon, Lyon, France, p. 245.

28 Integrated Study of Rolling Contact Fatigue. Final report, March 2000, European Union Brite-EuRam III Project ICON (Integrated study of rolling CONtact fatigue), Ref. BE96-3091, CIG funded supported research project, task 6, 2000.

29 Aknin, P., Pascal, J. P., Bettembourg, J. P. J. and Prasil, B. (1996) Contribution of railway dynamics codes to the understanding of the metallurgical behavior of the rail tread. Wear 191, 126-132.

30 Kapoor, A. (1994) A re-evaluation of the life to rupture of ductile metals by plastic strain. Fatigue Fract. Engng Mater. Struct. 17, 201-219. 
31 Eleod, A., Oucherif, F., Devecz, J. and Berthier, Y. (1999) Conception of numerical and experimental tools for study the tribological transformation of surface (TTS). In: Lubrication at the Frontier: Proceedings of the 26th Leeds-Lyon Symposium on Tribology, Lyon, France. Tribology Series, Vol. 36 (Edited by Dowson et al.). Elsevier, Amsterdam, pp. 673-682.

32 Rigney, D. A. (1992) Some thoughts on sliding wear. Wear 152, 187-192.

33 Niccolini, E. and Berthier, Y. (2002) Progression of "sticking and sliding" zones in a dry wheel-rail contact: updating theories on the basis of tribological reality. Proceedings of the 29th Leeds-Lyon Symposium on Tribology, Lyon, France. Tribology Series (Edited by Dowson et al.). Elsevier, Amsterdam, Vol. 41, pp. 845-853.

34 Iordanoff, Y., Seve, B. and Berthier, Y. (2002) Solid third body analysis using a discrete approach: Influence of adhesion and particle size on macroscopic properties., Trans. ASME 124, 530-538.

35 Descartes, S. and Berthier, Y. (2002) Rheology and flows of solid third bodies: background and application to an $\mathrm{MoS}_{1.6}$ coating. Wear 252, 546-556.

36 Coulon, S., Ville, F., Nélias, D., Numerical and experimental investigations on rolling contact fatigue for dented surfaces. In: Proceedings of the 27th Leeds-Lyon Symposium on Tribology. Tribology Series, (Edited by D. Dowson et al.). Elsevier, Amsterdam, Vol. 39. pp. 459-468.

37 Hill, R. J. and De La Vaissiere, J. F. (1997) A Fuzzy Wheel-Rail Adhesion Model for Rail Traction. EPE, Trondheim, pp. $416-421$.

38 Niccolini, E. and Berthier, Y. (2000) Wheel-rail adhesion: what is the tribological reality? In: Proceedings of the 5th International Conference on Contact Mechanics and Wear of Rail/Wheel Systems, Tokyo, 25-28 July pp. 219-225.

39 Niccolini, E. and Berthier, Y. (2003) Wheel rail adhesion: laboratory study of the role of the natural third body on wheels on locomotive and rails. In: Proceedings CM2003, 6th International Conference on Contact Mechanics and Wear of Rail/Wheel Systems, Gothenburg, Sweden, pp. 495-501.

40 Busquet, M., Baillet, L., Bordreuil, C. and Berthier, Y. (2003) $3 \mathrm{D}$ finite element investigation on the plastic flows of railheads, correlation with microstructural observations. In: Proceedings CM2003, 6th International Conference on Contact Mechanics and Wear of Rail/Wheel Systems, Gothenburg, Sweden, pp. 525-534.

41 Johnson, K. L. (1989) The strength of surfaces in rolling contact. Proc. Inst. Mech. Eng. 203, 151-163.

42 Aknin, P., et al. (1996) Contribution of railway dynamics codes to the understanding of the metallurgical behaviour of the rail tread. Wear 191, 126-132.

43 Dagorn, C. (2000) Master report '3D modelling of the wheel-rail contact', INSA Lyon (in French).

44 Chollet, H. (1999) Wheel/rail contact, Internal Report. INRETS (in French).

45 Eleod, A., Baillet, L., Berthier, Y. and Torkoly, T. (2002) Deformability of the near surface layer of the first body. In: Proceedings of the 29th Leeds-Lyon Symposium on Tribology, Leeds, Vol. 41. pp. 123-136.

46 Bridgman, P. W. (1964) Studies in Large Plastic Flow and Fracture, 2nd ed. Oxford University Press, London, p. 362.

47 Cai, C. B. C., Kuhlmann-Wilsdorf, D. and Nelson, R. B. (1991) A study of shear deformation and work hardening of metals under pressures to $2100 \mathrm{MPa}$. Mater. Sci. Engng 32, 103-128.

48 Yang, Y. (1997) PhD Thesis 'The prediction of the wear rates of ductile materials through their surface strains', Trinity College, University of Dublin.

49 Bower, A. F. and Johnson, K. L. (1989) The influence of strain hardening on cumulative plastic deformation in rolling and sliding line contact. 7. Mech. Phys. Solids 37, 471-493.

50 Ham, G. L., Hahn, G. T., Rubin, C. A. and Bhargava, V. (1989) Finite element analysis of the influence of kinematic hardening in two-dimensional, repeated, rolling-sliding contact. Tribology Trans. 32, 311-316.

51 Owell, M., Hahn, G. T., Rubin, C. and Mcdowell, D. L. (1995) Finite element analysis of rolling contact for nonlinear kinematic hardening bearing steel. f. Tribology 117, 729-736.

52 Kennedy, F. E. (1984) Thermal and thermomechanical effects in dry sliding. Wear 100, 453-476.

53 Kerouani, Y., Girardi, L., Berthier, Y., Baillet, L. and Dagorn, C. (2000) Identification of 'wear mechanisms' of the gauge-side of the rail in curves. Presented at the 5th International Conference on Contact Mechanics and Wear of Rail/Wheel Systems, Tokyo, 25-28 July. 